\section{REDIMAT}

Journal of Research in Mathematics Education
Hipatia Press

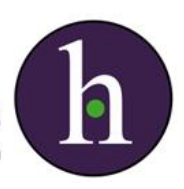

Instructions for authors, subscriptions and further details:

http://redimat.hipatiapress.com

\title{
Research Findings' Impact on the Representation of Proportional Reasoning in Swedish Mathematics Textbooks
}

Linda Marie Ahl ${ }^{1}$

1) Kriminalvården, Sweden

Date of publication: June $24^{\text {th }}, 2016$

Edition period: June 2016-October 2016

To cite this article: Ahl, L.M. (2016). Research findings' impact on the representation of proportional reasoning in Swedish Mathematics textbooks. REDIMAT, 5(2), 180-204. doi: 10.4471/redimat.2016.1987

To link this article: http://dx.doi.org/10.4471/redimat.2016.1987

PLEASE SCROLL DOWN FOR ARTICLE

The terms and conditions of use are related to the Open Journal System and to Creative Commons Attribution License (CC-BY). 


\section{Research Findings' Impact on the Representation of Proportional Reasoning in Swedish Mathematics Textbooks}

Linda Marie Ahl

Kriminalvården

(Received: 29 February 2016; Accepted: 15 June 2016; Published: 24 June 2016)

\section{Abstract}

This article investigates the impact of research findings on the representation of proportional reasoning in two commonly used Swedish mathematics textbook series for grades 7-9. A research-based framework that identifies five learning goals for understanding of proportional reasoning was used to analyse the textbooks. The results brought to surface a gap between research findings of important issues to address and the actual design of mathematics textbooks. Both textbook series make use of an effective range of representations. Besides that, the analysis shows low impact from research findings concerning the importance of given opportunities to compare and contrast additive and multiplicative situations, identify multiplicative structures and proportional thinking, make use of meaningful symbolic representations, and connect and relate fraction knowledge. The main conclusion is that there are possibilities for improvement in textbook design in relation to understanding proportional reasoning.

Keywords: Proportional reasoning, textbooks, representation, understanding 


\title{
Impacto de los Resultados de Investigación sobre la
}

\section{Representación del Razonamiento Proporcional en los Libros de Texto Suecos}

\author{
Linda Marie Ahl \\ Kriminalvården
}

(Recibido: 29 Febrero 2016; Aceptado: 15 Junio 2016; Publicado: 24 Junio 2016)

\section{Resumen}

Este artículo investiga el impacto de los resultados de una investigación sobre la representación del razonamiento proporcional en dos series de libros de texto suecos de matemáticas, para los grados 7-9. Se ha utilizado un marco basado en cinco objetivos de aprendizaje para la comprensión del razonamiento proporcional en los libros de texto. Los resultados revelan la existencia de una brecha entre lo que dice la investigación sobre los temas importantes a tratar y el diseño real de los libros de texto de matemáticas. Ambas series de manuales hacen uso de un elenco de representaciones simbólicas significativo. A pesar de eso, el análisis muestra un impacto bajo de los resultados de investigación en relación a la importancia de dar oportunidades para comparar y contrastar situaciones aditivas y multiplicativas, identificar estructuras de pensamiento proporcional, usar representaciones simbólicas y conectarlo con el conocimiento sobre fracciones. La conclusión principal es que existen posibilidades para mejorar el diseño de los libros de texto en relación al pensamiento proporcional.

Palabras clave: Pensamiento proporcional, libros de texto, representación, comprensión 
P

roportionality is a key concept in mathematics and science education from elementary school to university. Hence, proportional reasoning is a prerequisite for successful further studies in mathematics and science, as multiplicative relations underpin almost all number-related concepts studied in elementary school. In upper secondary school students make use of linear models and approximations in calculus and statistics and in university of higher-order concepts such as abstraction in a vector space sense. Despite the pervasive nature of proportional reasoning throughout school years it is well known that children around the world have considerable difficulty understanding the conceptual field of proportional reasoning, e.g., fractions, percentages, ratio, proportion, rates, similarity, trigonometry, and rates of change (Behr, Harel, Post, \& Lesh, 1992; Lamon, 2007).

From research we know a lot about students' hurdles with understanding proportional reasoning (to be elaborated on in the next section). We also know that textbooks may be teachers' most important tools in mathematics education. The concept of tool should in this article be understood as an artefact with power to shape human activity (Remillard, 2005). To interpret textbooks as tools have the implication that teachers and textbooks both have agency over the enacted teaching in a participatory relationship. A study by Grouws, Smith and Sztajn, (2000) show that if certain content is not included in the textbooks, it is likely that students will not be exposed to that content. Therefore the representation of proportional reasoning in textbooks is likely to have a great influence on students' learning opportunities. Vincent and Stacey (2008) found that some of the bestselling books in Australia emphasized memorization and procedures without connections. Also in Australia, Shield and Dole (2002) analysed textbooks for lower secondary school and found limitations in definitions for the topics of ratio, rate and proportion. Further studies on secondary school by Shield and Dole (2013) found limitations in the capacity of textbooks to promote students' deep connected understanding of proportional reasoning. Deep connected understanding refers to the competence to discover the underlying mathematical structure in a problem situation and being able to transmit mathematical knowledge to unfamiliar, but related contexts.

Mathematics textbooks play a very important role in Swedish teachers' planning and enactment of classroom practice. The Trends in Mathematics and Science study (Mullis et al., 2012) found that more than $90 \%$ of Swedish compulsory school students are taught on base of the structure in the 
textbook. Therefore it is of particular interest to study how textbooks represent proportional reasoning in order to get a picture of the base for teaching proportional reasoning. For upper secondary school, we know that Swedish textbooks for grade 10 are short of problems that require proportional reasoning and understanding of concepts (Lundberg, 2011). Most exercises in the analysed textbooks required no more than imitating the procedure presented in worked examples. Even so, we do not know how Swedish textbooks represent proportional reasoning for lower secondary school. This article focuses on the representation of proportional reasoning in Swedish mathematics textbooks in relation to what research findings stress to be important for building a deep connected understanding of proportional reasoning in grades 7 to 9 . The driving forces for conducting this study are the strong position of textbooks in the mathematics classroom in general together with teachers' faith in textbooks to convey the intentions and goals of mathematics education. This study adds to the knowledge base of research on how textbooks reflect research findings. The question that guides this study is: How do Swedish mathematics textbooks for grades 7 - 9 represent proportional reasoning in relation to five research-based key learning goals for developing deep connected understanding? Due to the importance of proportional reasoning this research area is highly relevant for everyone involved in mathematics education, yet particularly interesting for teachers and authors of curriculum materials. Further, this study contributes with the case from Sweden through the widespread use of the investigated textbooks.

\section{Related Research on Proportional Reasoning}

When scanning the literature on proportional reasoning it is evident that there is a large body of research, which seems to unanimously (1) agree that proportional reasoning is a cornerstone in mathematics and a prerequisite for successful further studies (cf. Behr et al., 1992; Karplus, Pulos, \& Stage, 1983; Lamon, 2007; Sowder et al., 1998); and (2) demonstrate that proportional reasoning is hard to define, and appears to be used as an umbrella term for anything referring to ratio, rate and proportion (Lamon, 2007). Thus, definitions in the conceptual field of proportional reasoning are not crystal clear. However, in the following section, the intention is to specify how the concepts present in the analysis are interpreted and defined in this article. The framework (Shield \& Dole, 2013) used for analysing the 
textbooks is built on decades of research on teaching and learning. From the literature they identified five keys for the development of proportional reasoning skills among students, to be elaborated on and explained in the following subsections.

\section{Key 1: Use of Authentic, Real-life Situations that Contrast Additive from Multiplicative Comparison}

In Sweden, children get acquainted with additive strategies for reasoning about quantities in grades 4 to 6 . For example, an increase in price by $10 \%$ can be calculated in two steps. First, calculate how much $10 \%$ is; and then, add this to the original price. In grades 7 to 9 , children are introduced to multiplicative situations and strategies for reasoning. Our price increase can now be approached in one multiplicative step: the original price multiplied by the factor 1.1 , to find the new price. We know that students have difficulty recognizing multiplicative situations and distinguishing them from additive situations (Fernández, Llininares, Van Dooren, DeBock \& Verschaffel, 2012). "Proportional reasoning entails the ability to distinguish additive from multiplicative comparisons, and knowing that a proportion situation exists when the comparison is multiplicative" (Dole \& Shield, 2008, p. 20). The difference between additive and multiplicative relationships is that the former requires reasoning about quantities. To exemplify, consider this problem:

Team A played a basketball game against Opponent A. Team B played a basketball game against Opponent B. The captains of Team A and Team B argued about which team beat its opponent by more. The captain of Team B won the argument by 8 points. Team A scored 79 points. Opponent A scored 48 points. Team B scored 73 points. How many points did Opponent B score? (Sowder et al., 1998, p. 133)

This problem involves enough complexity to require that the students make sense of the quantities involved (Sowder et al., 1998). It is not enough to simply apply a procedure to calculate the right answer; the problem requires reasoning about quantities in the additive relationships. In their early years, children rely on additive reasoning. Making the transition to being able to use both additive and multiplicative reasoning requires the ability to distinguish between the two kinds of reasoning. Therefore, it is important for students to encounter situations involving both additive and 
multiplicative comparisons (Van Dooren, De Bock, Vleugels, \& Verschaffel, 2010; Sowder et al., 1998), as in the following problem:

Dieter A: "I lost $1 / 8$ of my weight. I lost 19 pounds."

Dieter B: "I lost $1 / 6$ of my weight, and now you weigh 2 pounds less than I do."

How much weight did Dieter B lose? (Sowder et al., 1998, p. 137)

Both additive and multiplicative comparisons are necessary to solve this problem, which gives the student the opportunity to reflect on the different features of additive and multiplicative reasoning. The second key to be described overlaps the first. Being able to distinguish between additive and multiplicative situations requires that children recognize multiplicative relationships.

\section{Key 2: Identification of the Multiplicative Structure in Proportion Situations}

A critical part of proportional reasoning is the multiplicative relationship represented in the situation (cf. Van Dooren et al., 2010; Lamon, 2007; Dole \& Shield, 2008; Sowder et al., 1998). Identifying multiplicative relationships requires the ability to distinguish between additive and multiplicative situations (key 1). This is not an easy interpretation for children. If a multiplicative comparative relationship of ratio situations is present, comparing the ratios present in the situation can be approached through either "within" or "between" thinking. Comparing within ratios, using Freudenthal's (1978) definition, entails comparing the parts of the ratio from the same measure space:

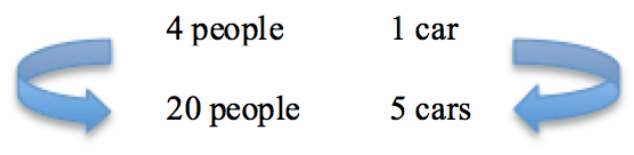

Figure 1. Comparing within ratios

So if 4 people need 1 car, 20 people will need 5 times as many cars. It is also important for children's understanding to highlight the inverse operation: if you know that 5 cars carry 20 people, 1 car will carry 20 people divided by 5 (Lamon, 2007). If we instead compare cars with people, the 
parts in the comparison of ratios come from different measure spaces and we have a between ratio comparison. Again, it is important to highlight to the children that the relation goes both ways: 5 cars times 4 gives a capacity to carry 20 people; and the inverse, 20 people divided by 4 tells us that we need 5 cars.

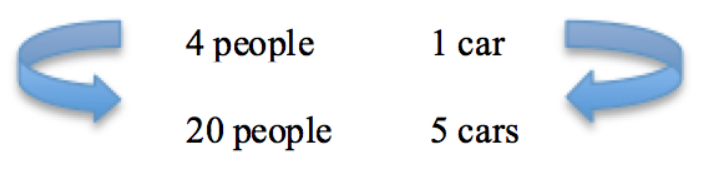

Figure 2. Comparing between ratios

To reach a deep understanding of proportional reasoning, it is important that children learn to reason both "within" and "between" quantities using both multiplication and division (Lamon, 2007; Shield \& Dole, 2013; Sowder et al, 1998).

\section{Key 3: Delay of Introduction of the Standard Proportion Algorithm}

Students are often taught to solve missing-value problems using the method of cross-multiplication, when there are three known values and one unknown (Karplus et al., 1983):

(1) Missing Value Problem: Yesterday I bought 28 candies with 12 quarters. Today, if I go to the same store with 15 quarters, how many candies can I buy? (Lo \& Watanabe, 1997, p. 218)

With cross-multiplication we get the equation $12 \square=15 \cdot 28$. While this is an easy way for students to approach missing-value problems, research has shown that it turns a proportion problem into an algebraic equation and prevents the understanding of proportional reasoning (Lamon, 2007; Shield \& Dole, 2008). Teaching how to solve missing-value problems is not synonymous with teaching proportional reasoning Students tend to apply this procedure without considering the nature of the problem. For example, without considering the applicability in the problem Farmer Gus needs 8 hours to fertilize a square pasture with sides of 200 meters. Approximately how much time will he need to fertilize a square pasture with sides of 600 meters? Applying proportionality will give the wrong (and unrealistic) answer of 24 hours (Van Dooren et al., 2010). To promote the understanding 
of the concept of proportion and avoid overuse of the cross-multiplication procedure, it should be delayed until students have attained an understanding of proportional reasoning. However, since procedures can be very helpful in solving problems involving proportional reasoning if one has attained a profound understanding of the multiplicative relationship represented in proportional situations (Lamon, 2007). Consider the comparison problem below, which can be solved with different approaches as well.

(2) Comparison Problem: Car A is driven $180 \mathrm{~km}$ for 3 hours. Car

$\mathrm{B}$ is driven $400 \mathrm{~km}$ for 7 hours. Which car is driven faster?

(Karplus et al., 1983, p. 220)

For this problem, the students need to compare the ratios 180/3 and 400/7 to determine which car is faster. Students can avoid the proportional reasoning part of the problem by using the method of manipulating the speed formula. Manipulating $s=v \cdot t$ will give the students average speed without considering a comparison of ratios (Karplus et al., 1983). Hence, if our learning goal is to promote students' understanding of proportional reasoning, we are in great danger of missing this goal if we teach them to manipulate formulas before they have had extensive opportunities to practice proportional reasoning.

\section{Key 4: Explicit Connection to Related Fraction Knowledge}

The difference between ratios and fractions is another source of confusion for children. For example, if a class of children consists of 15 girls and 14 boys, the part/whole fractions 15/29 and 14/29 arise. The part/part ratio between girls and boys is $15: 14$. When a ratio connects two parts of the same whole, children may not adequately recognize the difference between part/part and part/whole relationships (Clark, Berenson, \& Cavey, 2003). It is not easy for children to realize the difference that ratios consist of part/part comparison while the comparison in a fraction refers to part/whole, since ratios can be written in fraction form and obey the same mathematical laws as fractions (Shield \& Dole, 2002). This confusion becomes obvious when children work with the following kind of task:

(3) Anna takes 4 hours to paint a wall. Maria takes 6 hours. How

long will it take them to paint the wall if they work together?

Understanding that the part/part ratio 4:6 needs to be related to a whole, in this case 10 hours is difficult for children who lack an understanding of the difference between part/part and part/whole relations. 


\section{Key 5: Wide Range of Representations of Proportion Situations}

Proportionalities can be represented in different ways, e.g., with words, pictures, algebraic, with graphs or tables. Shield and Dole $(2008,2013)$ enhance the use of a range of representations to promote children's learning. If children are given the opportunity to work with graphs, tables and other diagrams that illustrate the proportional situation present in the mathematical task, their conceptual understanding is promoted. Their ability to see connections between tasks that are based on the same mathematical idea is also enhanced, e.g., the ability to see that missing-value problems regarding similarity, proportional functions and speed problems can be illustrated with different representations but approached with the same mathematical idea.

\section{Research Design}

\section{Context}

Being a cornerstone in mathematics education, proportional reasoning is pervasive in the Swedish National Curriculum for compulsory school in general, but yet specifically dominating for grades 7-9. The Swedish National Curriculum stresses development under 6 headings of so called central content namely; Number conception and use of numbers, Algebra, Probability and statistics, Connections and change, Geometry and Problem solving (Skolverket, 2011a; 2011b). All these mathematical topic involve proportional reasoning e.g., use of rational numbers, proportional formulas and equations, statistics over proportional situations, percental increase and decrease, similarity and all kinds of problem solving and modeling of proportional situations. Consequently a great deal of compulsory education aims at providing teaching situations where students are given the opportunities to grasp the mathematical idea of multiplicative relationships, in order to reason about outcomes under the given conditions.

Teachers in Sweden are free to choose which textbooks to use. Since the beginning of 1991, there is no state control and the textbooks available on the market are produced commercially. Since publishers' sales numbers are not official in Sweden, they cannot be used to reveal what textbooks teachers actually use in Swedish classrooms. Therefore my choice of textbooks is based on a questionnaire among all compulsory school mathematics teachers in the sixth largest municipality in Sweden. The questionnaire was 
distributed in August 2012 on a mandatory meeting the first workday after summer leave (Neuman, Hemmi, Ryve, \& Wiberg, 2015). Of a total of 329 teachers, 278 teachers responded to the question about which textbook they mainly use in instruction. The results showed that two textbooks series together covered $97 \%$ of the classrooms in grades 7-9. Based on the dominance of these textbooks in the questionnaire it is likely that they may be the most commonly used in Swedish classrooms. In this analysis they are called Textbook A (Matematik Direkt) and Textbook B (Matematikboken $\mathrm{XYZ}$ ). Both textbook A and B provide one textbook per grades 7, 8 and 9. Hence, altogether six textbooks are analyzed.

In Textbook A, content is organized in chapters with different mathematical topics, e.g., Number; Geometry; Functions et cetera. Every chapter (6 chapters per grade) starts with a description of the content and the goals for working with the chapter. At the top of each page or spread there is a square containing key concepts relating to the exercises. There are few worked examples in the textbook, and when they are present they are presented in the square. The intention of the authors (explicitly written out in the beginning) is that all students should work with a Basic course. After this, they perform a diagnosis. Depending on the results, the students then continue with either a Blue course, slightly easier than the Basic course, or a Red course, which is more demanding than the Basic course. Both the Blue course and the Red course are included in the chapter, allowing students to go back and forth between the courses and work with tasks on different levels of difficulty. The chapter closes with a summary and a spread with more demanding problems.

Also in Textbook B, content is organized in chapters with different mathematical topics. Every chapter ( 7 chapters per grade) starts with a list of goals for that chapter and a summary of key concepts the students will encounter. Then follows a number of sections containing theory, worked examples and tasks on four levels, where level 1 is the most basic and level 4 the most demanding. The intention of the authors (explicitly written out in the beginning) is that the students should work with two consecutive levels, e.g., level 1 and 2 or level 2 and 3 etcetera. The chapter closes with a summary and a set of mixed tasks on different levels. Each chapter also includes a diagnosis, extra tasks for those who need more practice and problem solving. 


\section{Method and Framework for Analysis}

This study investigates the above-described textbooks representation of proportional reasoning through the lenses of a framework with five researchbased learning goals. The study is a part of a larger study where both textbooks and their teacher guides are investigated. A content analysis in three steps where made in the beginning of year 2014. The analysis commenced by summarizing the disposition in the textbooks. Thereafter, I documented which parts of the textbooks covered representations of ratio, proportions and proportional reasoning. I read the instructions to the students and scanned the textbook for worked examples giving the students blueprints for how to approach the tasks. Finally I solved all exercises, tasks and problems to get a picture of where proportional reasoning where applicable. Altogether six textbooks where analyzed. Grade 7, 8, and 9 for both textbook series respectively. The analysis is delimited to the sections concerning proportional reasoning. For the preparation of this article, to refresh my memory and check my earlier understanding, I returned to the analysis of the six textbooks in the beginning of 2015 .

Textbook analyses can focus on a range of various aspects e.g., cognition and pedagogy; culture and value and mathematics content and topics (for more information see Fan, Zhu, \& Miao, 2013). Aiming to capture the connectedness in the conceptual field of proportional reasoning (Vergnaud, 1983, 2009), I used Shield and Dole's (2013, pp. 8-9) framework to analyze the textbooks representation of proportional reasoning. The reason for my choice is twofold. First Shield and Dole developed their framework from the theoretical assumption that textbooks are artifacts, following the sociocultural tradition that also guides this study. Second, they acknowledge Vergnaud's (1983, 2009) Theory of conceptual fields for multiplicative structures, which emphasizes the importance of developing students' understanding of structured links and connectedness within and between topics. The framework addresses the potential support textbooks offer children in developing a deep and connected understanding of proportional reasoning. It is developed from the described five key points for deep connected understanding of proportional reasoning (see section: Related research). The five key points is represented as five learning goals in the framework. Each learning goal has three indicators to support identification of the representation. The indicators, as well as the learning goals, stem from decades of research findings on proportional reasoning. 


\section{Findings}

This section presents the results of the examination of the two textbook series addressing the indicators of each learning goal. The indicators focused the attention on research findings impact on the representation of proportional reasoning in two commonly used Swedish mathematics textbooks for grades 7-9. The findings are organized under the five learning goals in the framework defined by Shield and Dole (2013). In Textbook series A, proportion is introduced in grade 7 and proportionality in grade 8 . The set-up differs in Textbook series B, where both proportion and proportionality are introduced in grade 9 .

\section{Learning Goal 1: Additive and Multiplicative Comparison Contrasted through the Use of Authentic Life-related Situations}

Indicators:

(a) Opportunities to differentiate between additive and multiplicative comparisons are provided.

(b) The multiplicative relationship in proportional situations is made explicit (cf. the additive nature of non-proportional comparisons).

(c) Examples and exercises use authentic comparisons

Both textbook series have made an effort to present exercises, tasks and problems in an every-day context, presumably familiar to most students. However, none of the six analyzed textbooks provide any opportunities to compare and contrast additive and multiplicative situations. The multiplicative relationship in proportional situations is not made explicit or compared with non-proportional situations. The importance of providing additive and multiplicative comparison contrasted through use of authentic life-related situations has not been paid attention to by the authors.

\section{Learning Goal 2: Identification of Multiplicative Structure and Proportional Thinking}

Indicators:

(a) Multiplicative comparative relationship of ratio situations is clearly defined. 
(b) Use of the operations of multiplication and division is highlighted (inverse).

(c) Use of both within and between thinking is evident.

In the Textbook $\mathrm{A}$ ratio is defined as equivalent to proportion and illustrated with an example (ratio is equivalent to förhållande in Swedish).

\section{Förhållanden - proportioner}

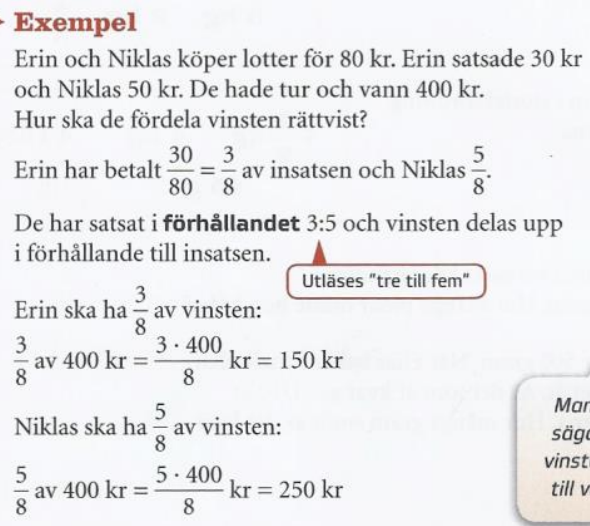

Figure 3. Introduction to ratios - proportions in Textbook A (grade 7, p. 160)

The example involves a ratio of bets and shows how to calculate two persons share of a lottery prize, in relation to their bets 3:5. There is no explicit definition of the concept ratio as a comparison between how quantities relate to each other. However, it is clear that the lottery prize should be shared in the same ratio as the bets, 3:5. So, the multiplicative comparative relationship of ratio situations is clearly defined for this situation. The following exercises are all about sharing bets. The question is if the students will grasp that the multiplicative relationship is present in all ratio situations, or if they isolate these phenomena to sharing lottery prizes.

In Textbook B, ratio is introduced as equal to proportion with a picture of yellow and green marbles. The picture illustrates the ratio between the numbers of yellow to green marbles. Also in Textbook B there is no written definition of ratio or proportion. 


\title{
2.5 Proportion
}

\author{
Vad menas med proportion? \\ På bilden ser du 6 gula och 8 gröna kulor. \\ Vi säger då att proportionen mellan \\ antalet gula och antalet gröna kulor är $\frac{6}{8}$. \\ Om vi förkortar med 2 får vi bråket i enklaste form. I enklaste form är \\ alltså proportionen mellan antalet gula och gröna kulor $\frac{6 / 2}{8 / 2}=\frac{3}{4}$. \\ Det kan också skrivas $3: 4$ och utläses "tre till fyra". Ett annat sätt att \\ uttrycka det är att antalet gula och antalet gröna kulor förhåller sig som \\ $3: 4$. \\ Vi kan också vända på det och istället uttrycka proportionen mellan \\ antalet gröna och gula kulor. Eftersom det är 8 gröna och 6 gula kulor \\ får vi att proportionen är $\frac{8}{6}=\frac{8 / 2}{6 / 2}=\frac{4}{3}$. Det kan också kan skrivas \\ $4: 3$ och uttalas "fyra till tre".
}

Figure 4. Introduction to proportion in Textbook B (grade 9, p. 87)

The ratio between the yellow and green marbles is simplified by 2 , but the multiplicative structure is not highlighted. This example is followed by "To calculate with proportions", where the multiplicative relationship could have been made clearly visible. But the authors choose to emphasize the formal proportion equation, which I will return to under learning goal 3Meaningful symbolic representation. It is interesting that both Textbook A and $\mathrm{B}$ avoid introducing formal written definitions of ratio, when one could argue that it is a strength in the subject mathematics that concepts have clear definitions for the students to rely on.

Mastering within and between strategies is important for solving problems that require proportional reasoning. Even so, neither Textbook A nor B demonstrates how to work with these strategies to solve missing value and ratio comparison problems. Neither Textbook A nor B highlights inverse operations to support the identification of a multiplicative structure. Working within- or between proportion strategies for proportional reasoning are not demonstrated in any of the six analyzed textbooks. 


\section{Learning Goal 3: Meaningful Symbolic Representation}

Indicators:

(a) Representation supports identification of within and between relationships in the proportion situation.

(b) Links between symbolic representation across problem types are made explicit (i.e., solution procedures are based on consistent symbolic representation for problems that share the same structure).

(c) Introduction of the formal "proportion equation" is delayed until extensive experience with other representations has been attained.

As a consequence of the lack of demonstration of within and between strategies the support for identification of within and between strategies are missing. I found no explicit links between solutions procedures based on consistent symbolic representation for problems that share the same structure e.g., those missing value problems with speed, similarity, price per unit et cetera, which could be approached with the same reasoning. While searching, without finding, the presence of within and between strategies, I found different approaches by authors of Textbook series A and B for introducing procedures. Procedures for calculation are rare in the Basic course in Textbook A. However, a different approach is taken in the more demanding Red course, which often introduces a calculation procedure together with the introduction of new mathematical content. The first time students get the opportunity to work with missing value problems is in the Red course. Textbook A demonstrate the following procedure in a worked example:

\section{Räkna med proportionaliteter}

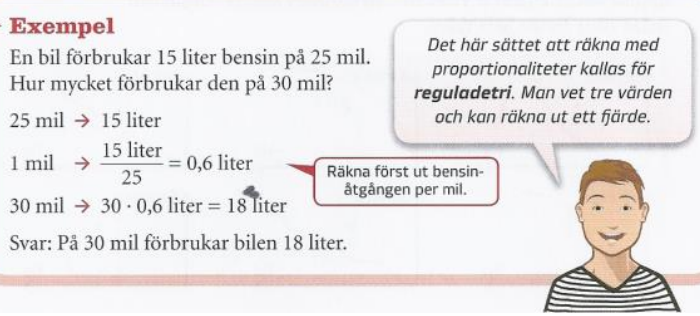

Figure 5. How much gas is used for 300 kilometres? Textbook A (Grade 9, p. 87) 
The method of calculating the unit rate, in this case liters/mile, and then multiplying by 30 miles (cf. 300 kilometers), is a productive way to calculate an answer, yet research has shown that the early introduction of procedures hinders the understanding of proportional reasoning. Students tend to apply procedures to all kinds of problems that at first glance look like missing value problems (Lamon, 2007). The authors' choice to introduce calculation methods only for students studying the more demanding Red course seems to be due to awareness that procedure may hinder the understanding. As described earlier (in the context section), the intended path for working with the textbook is to first study the Basic course, where procedures rarely are introduced, and then either the Blue or Red course. Presumably the students have had enough opportunities to practice to be introduced to procedures without blurring their understanding. Something that contradicts a conscious choice of consequently delaying the introduction of procedures is that average speed is introduced in the Basic course (Textbook A, grade 7, p. 50) with manipulation of formula $s=v \cdot t$, without giving the students opportunities to approach the problems with intuition. Introduction of procedures and worked examples in the basic course occurs only on one other occasion, when length scale, area scale and volume scale is introduced in grade 9.

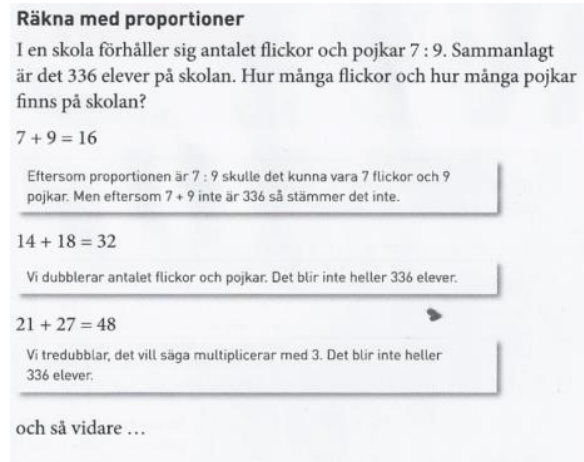

Så här kan vi fortsätta tills vi hittar vilket tal vi ska multiplicera med så att summan av flickor och pojkar blir 336. Men det finns ett enklare sätt. Vi tecknar en ekvation.

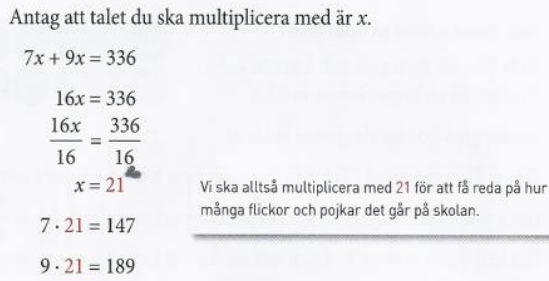

Det går alltså 147 flickor och 189 pojkar på skolan, vilket tillsammans blir 336 elever.

Figure 6. How to calculate with proportions, Textbook B (grade 9, p.87)

A different pattern is evident in Textbook B where a calculation procedure is introduced together with the introduction of new mathematical 
concepts. Figure 6 shows what follows the introduction of ratio showed in figure 4 above (under Learning goal 2). Textbook B continues with an example for how to calculate with proportion (see Figure 6).

The example is about a school where the ratio of girls to boys is 7:9. There are 336 students at the school. The question is: How many are girls and how many are boys? The text explains that: Since the proportion is 7:9 there could be 7 girls and 9 boys, but that is not equal to 336, so this cannot be right. Then the authors double the entities of girls and boys $(14+18=32)$, and still do not reach 336 students. They triple $(21+27=48)$, multiply by three, and still do not reach 336 students. Then the authors conclude that we can keep doing this until we reach the integer to multiply by in order to reach 336 students. Finally the authors introduce the formal proportion equation and stress that this is an easier way to solve the problem: $7 x+9 x=$ 336.

Mastering within and between strategies is important for solving problems that require proportional reasoning. This problem is easily solved with proportional reasoning (within strategy: 16 times 21 equals 336, hence 9 times 21 gives us the amount of boys and the rest are girls, or 7 times 21 if you prefer). The authors have opportunity to show a within strategy since they start with doubling the quantities in the ratio, twice. The introduction of an equation makes the student miss the opportunity to practice proportional reasoning. In another section, similarity is introduced together with the method of cross-multiplication (Textbook B, grade 9, p. 114), instead of giving the students opportunities to use reasoning to search for the proportionality constant between the lengths of the sides of a triangle. So the opportunity to show links between symbolic representations across problem types is not made explicit.

\section{Learning Goal 4: Related Fraction Ideas Explicitly Connected}

Indicators:

(a) Clear links are made with ideas of fractions and equivalence.

(b) Part/whole fraction and part/part/whole ratio relationships are explicitly distinguished.

(c) Fraction notation meaning in use (e.g., part/whole, ratio, and quotient) is clearly signalled.

In Textbook A, ratio and proportion are introduced in grade 7, p.160 (see figure 3 above), but only for the children studying the more demanding Red 
course. In figure $\mathrm{x}$ we can see a highlighting of clear links with ideas of fractions and equivalence when the fraction 30/80 is simplified to $3 / 8$. Also part/whole fraction and part/part ratio relationships are explicitly distinguished. Fraction notation meaning in use (e.g., part/whole, ratio, and quotient) is signaled by the calculation of $3 / 8$ of $400 ; 5 / 8$ from 400 and the explanation of ratio 3:5. However, at no point does the text mention that $3: 5$ means part/part ratio and $3 / 8$ part /whole fraction.

Textbook B (grade 9, p. 87) uses the $6 / 8$ to introduce proportions (see figure 4 above). This is simplified to $3 / 4$, showing clear links between fractions and equivalence. The notion $3: 4$ and $4: 3$ is explicitly written out as ways to express the number of yellow to green marbles and vice versa. There are no distinctions between part/part ratio and part/whole fractions. There are no explicit definitions of the meaning of $\mathrm{a} / \mathrm{b}$ in use in Textbook $\mathrm{B}$.

\section{Learning Goal 5: Effective Use of a Range of Representations}

Indicators:

(a) Tables are used to highlight multiplicative relationships.

(b) Graphs of proportional situations are straight lines that go through the origin.

(c) Graphs are used to extrapolate and interpolate solutions and/or make predictions.

Both textbooks make use of a range of representations to illustrate that graphs of proportional situations are straight lines that go through the origin. The multiplicative situation in proportion situations is made explicit in both textbook series, mainly with a range of proportional graphs that are contrasted to other nonlinear graphs. Tables, used to highlight multiplicative relationships in both textbooks, illustrate both non-proportional linear functions and proportionalities. By explicitly stating that the proportionalities depend only on price per kilogram or hour, the multiplicative nature of proportionalities is highlighted. The introductions to proportionalities are very similar in the two textbooks. In Textbook A the concept proportionality is introduced in grade 8 and repeated in grade 9. This example is from Textbook A: 


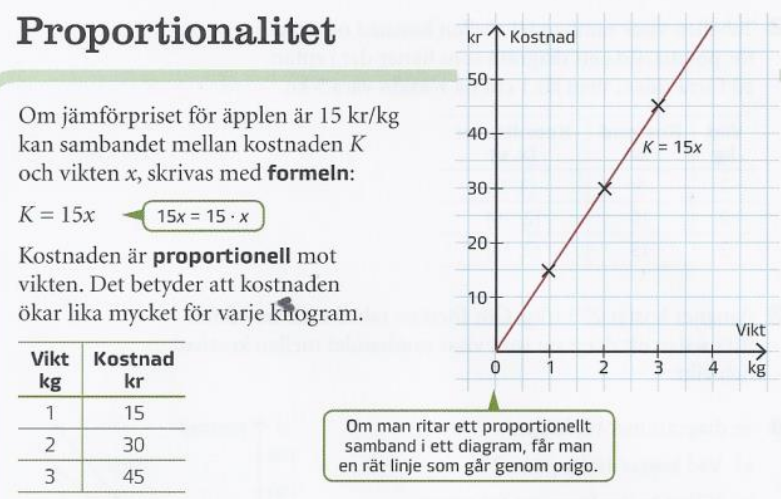

Ett proportionellt samband kallas också en proportionalitet.

Figure 7. Proportionality, Textbook A, (grade 8, p. 114)

The text says that if the price is $15 \mathrm{SEK} / \mathrm{kg}$, the connection between cost, $\mathrm{K}$, and weight, $\mathrm{x}$, can be written with the formula: $\mathrm{K}=15 \mathrm{x} ;(15 \mathrm{x}=15 \cdot \mathrm{x})$. Further the text explains that the cost is proportional to the weight, meaning that the cost increases by the same amount per kilogram. This is illustrated in a table and finally with a graph, with the explicit comment that all proportionalities go through the origin. A very similar example is used to introduce proportionalities in Textbook B (see Figure 8).

The text explains proportionality with an example from a grocery store where kiwi fruits cost 40 SEK per kilogram. Two kilos cost $40 \times 2$ SEK $=80$ SEK and three kilos cost $40 \times 3 \mathrm{SEK}=120 \mathrm{SEK}$. Therefore $\mathrm{X}$ kilos cost 40 $\times \mathrm{X}$ SEK $=40 \times$ SEK. Like in Textbook A, this is illustrated in a table and finally with a graph, with the explicit comment that all proportionalities go through the origin.

These examples of different representations illustrate the multiplicative structure of proportionality between price and weight by emphasizing that the cost increases by the same amount per weight unit. The exercises in both textbooks provide comparisons with non-proportional situations. As mentioned, the multiplicative situation in proportion situations is made explicit in both textbook series with a range of proportional graphs contrasted to other, nonlinear, graphs. However, there are no comparisons with additive discrete situations, illustrated through graphs or any other 
representation. Both textbook series also lack graphs used to extrapolate and interpolate solutions and/or make predictions.

\subsection{Proportionalitet}

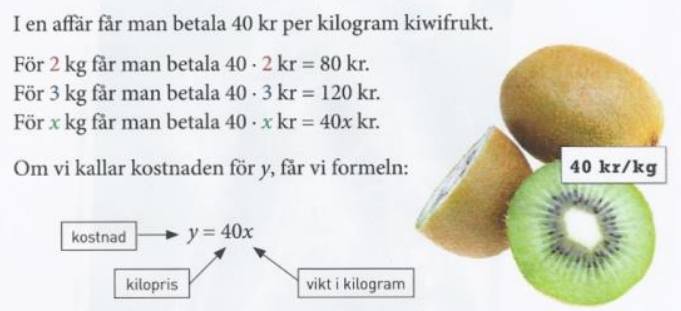

Formeln gäller för alla priser och vikter. Kostnaden beror av hur många kilogram man köper. Priset är en funktion av vikten.

Kostnaden är i det här fallet proportionell mot antalet kilogram. Det betyder att om man till exempel köper dubbelt så stor vikt får man betala dubbelt så mycket.

Vi gör en värdetabell och ritar grafen som visar kostnaden som funktion av vikten. Längs $x$-axeln avsätter vi vikten och längs $y$-axeln avsätter vi kostnaden.

\begin{tabular}{|c|c|}
\hline$x$ & \multicolumn{1}{|c|}{$y$} \\
\hline 0 & 0 \\
\hline 1 & 40 \\
\hline 2 & 80 \\
\hline
\end{tabular}

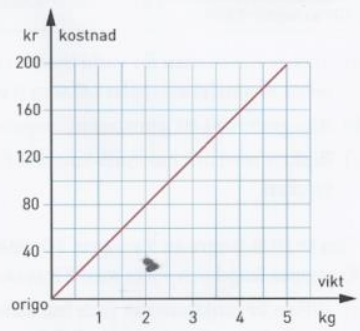

Grafen till en proportionalitet går alltid genom origo.

Figure 8. Proportionality, Textbook B, (grade 9, p. 196)

Thus, both textbook series make use of an effective range of representations (learning goal 5). For the other learning goals the analysis shows low impact from research findings concerning the importance of being given opportunities to 1) compare and contrast additive and multiplicative situations, 2) identify multiplicative structures and proportional thinking, 3) make use of meaningful symbolic representation, and 4) connect and relate fraction knowledge. 


\section{Discussion}

This article focuses on the representation of proportional reasoning in Swedish mathematics textbooks in relation to what research findings stress to be important for building a deep understanding of proportional reasoning in grades 7 to 9. The question that guides this study is: How is proportional reasoning represented in relation to five research-based learning goals in Swedish mathematics textbooks for grades 7 - 9? The analysis of the two textbook series through the lenses of Shield and Dole's (2008) suggests that the impact of research findings on the representation of proportional reasoning is scant. A possible explanation for this may be that research findings have difficulty to reach the authors, or the other way around. The authors may have difficulty to digest and select among the numerous studies of research presented.

Strengths in both textbooks are the uses of a wide range of representations of proportional situations (key 5). However, the support for understanding proportional reasoning may be hindered by the absence of representation of within and between thinking in both textbooks series (see key 2: Identification of the multiplicative relationship represented in the situation). When understanding this underlying common structure, it is possible for students to approach all these problems, as they are variations over the same kind of problem. As acknowledged in the literature review, the critical part of proportional reasoning is the multiplicative relationship represented in the situation (cf. Dole \& Shield, 2008; Fernández et al., 2012; Lamon, 2007; Sowder et al., 1998; Van Dooren et al., 2010). Multiplicative relationships require the ability to distinguish between additive and multiplicative situations (see key 1: Use of authentic, real life situations that contrast additive from multiplicative comparison). Further, students are often confused about the difference between ratios and fractions (see key 4: Explicit connection to related fraction knowledge). None of these issues are addressed in the textbooks. This may be one part of the problem with the difficulties students have with learning proportional reasoning, since a previous study show that if a certain content is not included in the curriculum resources, it is likely that students will not be exposed to that content (Grouws, Smith, \& Sztajn, 2004). Together with the current state of affairs, where Swedish teachers often base their planning solely on textbooks, the representation of content may have strong impact on students' learning. To promote the understanding of proportional situations, the 
textbooks need to highlight proportional reasoning, instead of introducing different solution methods for problems that share the same underlying multiplicative structure. As described in the analysis, the textbooks differ in how procedures are introduced. Textbook A seldom introduces procedures in the Basic course. Only on two occasions procedures and worked examples are introduced in the Basic course, concerning average speed in grade 7 and length scale, area scale and volume scale in grade 9. The lack of worked examples in the Basic course can support the students in approaching the problems with an open mind (not chained by procedures), which supports the understanding of proportional reasoning (Lamon, 2007). For the more demanding Red course in Textbook A, different calculation methods for tasks in different topics are introduced at the same time as new mathematical content. Also in Textbook B the students are given different methods for average speed, scale, ratio and proportion problems without being explicitly introduced to the underlying multiplicative structure, which risks them getting the impression that the problems are essentially different. The worked examples introduce procedures at the same time that new content is introduced. This can be supportive for teachers, as it gives the opportunity to offload instruction to the textbook. However, before doing so the teacher must consider the authors' rationales for the chosen scripted instructions. Are they relying on research findings, tradition, discourse, interpretation of the national curriculum, or perhaps the instructions mirror the authors' own experiences as mathematics learners? More important, do they align with the teacher's own beliefs about mathematics education? As mentioned, for learning proportional reasoning, procedures should be delayed until students have had the opportunity to work with proportional reasoning problems without scripted solution methods. Thus, even though it can be supportive for teachers to have the ability to offload instruction to textbooks, in this case the analysis shows that it may not support the students' understanding. On the contrary, it may hinder students' understanding. The teacher can choose to interact with the textbook in different ways: follow the textbook and emphasize the same solution method, or present another way to approach the problems. A hurdle for the teacher is that the students have access to the solution methods presented in the textbook, which might undermine the teacher's endeavor to approach problems in different ways. Procedure is seductive to students, as it often represents a fast way to get an answer (Lamon, 2007). Therefore, the introduction of procedures can constrain the teacher's agency in the classroom. 


\section{Ahl-Proportional Reasoning in Swedish Mathematics Textbooks}

Considering the scope of this study, I adopt the theoretical stance, sprung from the sociocultural tradition, that textbooks are artifacts with power to shape human activities. Therefore this study says nothing about the actual teaching that will occur using these textbooks. Teaching is a result of an interaction where both teacher and textbooks contribute with resources e.g., for the teacher his or her beliefs, education and experience and for textbooks their structure, choice of content, voice, etcetera. Since the teacher is the single most important factor for the outcome of teaching it may seem redundant to analyze textbooks in isolation from their actual use. But since textbooks have a great impact on teachers' planning and enactment of teaching, I argue that a study of teachers' actual use of textbooks in a classroom context will be hard to interpret without foregoing analyses of both the textbook as a 'dead tool', before it comes to life in the hands of the teacher, as well as the personal resources that the teacher brings to this interaction.

This study provides insights of the impact from research findings on proportional reasoning, represented with five key points, for developing deep connected understanding of proportional reasoning in two commonly used textbook series in Swedish lower secondary school, grades 7-9. The results broaden Lundberg's findings (2011) that Swedish textbooks for grade 10 are short of problems requiring proportional reasoning and relational understanding of concepts. Most exercises in the analyzed textbooks required no more than imitating the procedure presented in worked examples. Similar results are shown for textbooks in Australia. Shield and Dole (2013) found that five commonly used textbooks series showed low potential to promote deep understanding of proportional reasoning.

The analysis may provide authors of textbooks with valuable information to consider for textbook structure and sequencing. But even without any change of the representation of proportional reasoning, teachers could use the results to make decisions about how to use their textbooks. As rationales for the learning goals are gathered from research on the topic, teachers could use the results to reconsider how to organize the content to better support deep connected understanding of proportional reasoning. At the end of the day the textbooks remain as only one tool for teaching. The single most important factor for the actual outcome of the enacted teaching is the teacher. Therefore awareness about strengths and limitations in textbooks may be enough to over-win the obstacles. 
Considering the revealed representation of proportional reasoning in the analyzed textbooks, it is possible that connections between topics may be hindered by the standard textbook design to structure mathematical topics in chapters e.g., numbers, geometry, functions, which may be perceived as watertight bulkheads by the students. The common mathematical idea of proportional relationships is covered under different solution methods for different topics. Drawing on the results from this study, I suggest another possible approach to the representation of proportional reasoning in textbooks.

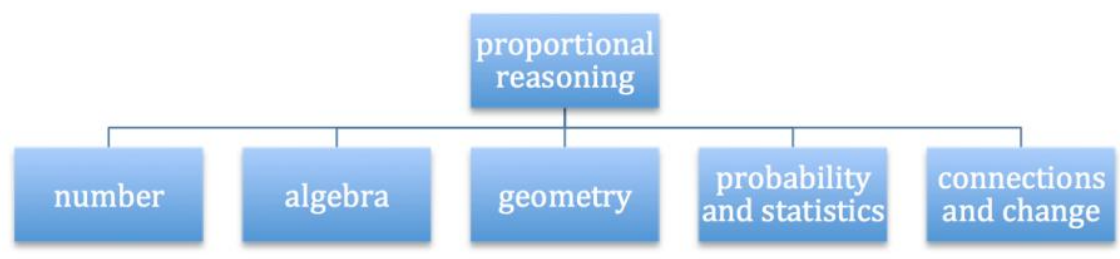

Figure 9. Connecting topics with the mathematical idea of multiplicative structures and proportional reasoning

The common mathematical idea of proportional relationships is covered under different solution methods for different topics. Drawing on the results from this study, I suggest, in line with Vergnaud (1993, 2009), to alter the presentation of proportional reasoning in Swedish textbooks, so that the mathematical idea of multiplicative structures and proportional reasoning is explicitly highlighted under every topic in the textbook. Also, drawing connections between the different topics in the textbooks may illustrate that the same reasoning is applicable in a range of various situations, and hence may enable both students and teachers to grasp the power of proportional reasoning. Finally, further research should focus on how to design actual teaching sequences with an emphasis on the five keys for understanding proportional reasoning through a connection of topics, putting to work the accumulated research results and findings.

\section{References}

Behr, M. J., Harel, G., Post, T., \& Lesh, R. (1992). Rational number, ratio, and proportion. In D.A. Grouws (Ed.), Handbook of research on mathematics teaching and learning (pp. 296-333). New York: Macmillan. 
Carlsson, S., Hake, K. B., \& Öberg, B. (2011). Matte direkt: år 7,8,9 [Mathematics direct: year 7]. Sanoma utbildning: Stockholm. Clark, M. R., Berenson, S. B., \& Cavey, L.O. (2003). A comparison of ratios and fractions and their roles as tools in proportional reasoning. Journal of Mathematical Behavior, 22(3), 297-317.

Dole, S., \& Shield, M. (2008). The capacity of two Australian eighth-grade textbooks for promoting proportional reasoning. Research in Mathematics Education, 10(1), 19-35.

Fan, L., Zhu, Y., \& Miao, Z. (2013). Textbook research in mathematics education: development status and directions. ZDM The International Journal on Mathematics Education, 45(5), 633-646.

Fernández, C., Llinares, S., Van Dooren, W., De Bock, D., \& Verschaffel, L. (2012). The development of students' use of additive and proportional methods along primary and secondary school. European journal of psychology of education, 27(3), 421-438.

Freudenthal, H. (1978). Weeding and Sowing: Preface to a science of mathematical education. Dordrecht, The Netherlands: D. Reidel. Grouws, D. A., Smith, M. S., \& Sztajn, P. (2000). The preparation and teaching practices of United States mathematics teachers: Grades 4 and 8. In P. Kloosterman \& F. Lester (Eds.), The 1990 through 2000 mathematics assessments of the National Assessment of Educational Progress: Results and Interpretations (pp. 221-267). Reston, VA: National Council of Teachers of Mathematics.

Karplus, R., Pulos, S., \& Stage, E. K. (1983). Early adolescents' proportional reasoning on 'rate' problems. Educational studies in Mathematics, 14(3), 219-233.

Lamon, S. J. (2007). Rational numbers and proportional reasoning: Toward a theoretical framework for research. In F. Lester (Ed.), Second handbook of research on mathematics teaching and learning, (pp. 629-666). Reston, VA: National Council of Teachers of Mathematics.

Lo, J. J., \& Watanabe, T. (1997). Developing ratio and proportion schemes: A story of a fifth grader. Journal for Research in Mathematics Education, 28(2), 216-236. 
Lundberg, A. (2011). Proportionalitetsbegreppet i den svenska gymnasiematematiken: en studie om läromedel och nationella prov. [The concept of proportionality in the Swedish upper secondary mathematics: A study of textbooks and national tests]. (Licentiate thesis, Linköping universitet, 2011:44). Linköping: Linköping University.

Mullis, I. V., Martin, M. O., Foy, P., \& Arora, A. (2012). TIMSS 2011 international results in mathematics. International Association for the Evaluation of Educational Achievement. Herengracht 487, Amsterdam, 1017 BT, The Netherlands.

Neuman, J., Hemmi, K., Ryve, A., \& Wiberg, M. (2015). Mathematics textbooks' impact on classroom instruction: Examining the views of 278 Swedish teachers. In H. Silfverberg, T. Kärki \& M.S. Hannula (Eds.), Nordic research in mathematics education - proceedings of NORMA14, Turku, June 3-6, 2014. Turku: The Finnish Research Association for Subject Didactics.

Remillard, J.T. (2005). Examining key concepts in research on teachers' use of mathematics curricula. Review of Educational Research, 75(2), 211-246.

Shield, M. J, \& Dole, S. (2002). Investigating Textbook Presentations of Ratio and Proportion. In B. Barton, K.C. Irwin, M. Pfannkuch, \& M. O. J. Thomas. Mathematics Education in the South Pacific. Proceedings of the Twenty-fifth Annual Conference of the Mathematics Education Research Group of Australasia (608-616). MERGA 25, Auckland, N.Z.

Shield, M. J, \& Dole, S. (2013). Assessing the potential of mathematics textbooks to promote deep learning. Educational Studies in Mathematics, 82(2), 183-199.

Shield, M. J., \& Dole, S. (2008). Proportion in middle-school mathematics:

It's everywhere. The Australian Mathematics Teacher, 64(3), 10-15.

Skolverket (2011a). Läroplan för Grundskolan, förskoleklassen och fritidshemmet 2011 [Curriculum for the compulsory school, preschool class and the leisure-time center 2011]. Stockholm: Fritzes. Skolverket (2011b). Kommentarmaterial till kursplanen i matematik [Comment materials for curriculum in mathematics]. Stockholm: Fritzes. 
Sowder, J., Armstrong, B., Lamon, S., Simon, M., Sowder, L., \& Thompson, A. (1998). Educating teachers to teach multiplicative structures in the middle grades. Journal of Mathematics Teacher Education, 1(2), 127-155.

Undvall, L., Johnson, K., \& Welén, C. (2012). Matematikboken X, Y, Z:

[för grundskolans senare år]. Lärobok [Mathematics book X].

Stockholm: Liber.

Van Dooren, W., De Bock, D., Vleugels, K., \& Verschaffel, L. (2010). Just answering... or thinking? Contrasting pupils' solutions and classifications of missing-value word problems. Mathematical Thinking and Learning, 12(1), 20-35.

Vergnaud, G. (1983). Multiplicative structures. In R. Lesh \& M. Landau

(Eds.), Acquisition of mathematics concepts and processes (pp. 127174). Orlando, FL: Academic.

Vergnaud, G. (2009). The theory of conceptual fields. Human development, 52(2), 83-94.

Vincent, J., \& Stacey, K. (2008). Do mathematics textbooks cultivate shallow teaching? Applying the TIMSS video study criteria to Australian eighth-grade mathematics textbooks. Mathematics Education Research Journal, 20(1), 82-107.

Linda M. Ahl is lecturer in mathematics education at Kriminalvården, Sweden.

Contact Address: Direct correspondence concerning this article, should be addressed to the author. Postal address: Box 1143, Stinsvägen 7, 72128 Västerås. Email: linda.ahl2@kriminalvarden.se 